\title{
The effect of an educational program using a group-based workshop to improve long-term care adherence in diabetic patients at risk of foot lesions
}

\author{
Gladys Pérez-Borges *, Juana Ledesma-Machado, Onelia Espinosa-Ramos, Carmen D. Mesa-Correa, Lourdes \\ Tort-Cursellas, Leonor Hernández-Hernández \\ Department of Clinical Nutrition and Endocrinology, Hospital Universitario de Canarias, Tenerife, Spain
}

Received: October 27, 2014

DOI: $10.5430 /$ jnep.v5n4p122
Accepted: February 2, $2015 \quad$ Online Published: March 2, 2015

URL: http://dx.doi.org/10.5430/jnep.v5n4p122

\begin{abstract}
The aim of this study was to evaluate the effect of a nurse-led educational intervention using group-based workshops in terms of changes in diabetic patient knowledge and skills to prevent foot lesions in 59 diabetic patients at risk of foot ulcers. The program focused on preventive care issues: shoes, foot inspection, nail cutting, hygiene, and general care of foot ulcers. After the educational intervention, mean care score increased significantly ( $40 \pm 7$ out of 50 points) compared with pre-workshop scores $(25 \pm 11 ; P<.001)$. No clinically relevant lesions were detected during follow up, and the incidence of foot lesions was lower compared with pre-workshop [20/59 (33.9\%) vs. 11/59 (18.6\%); $P=.03$ ]. In conclusion, group-based workshop education on the diabetic foot improves care skills and decreases the long-term incidence of foot lesions.
\end{abstract}

Key Words: Diabetic foot, Intervention, Group-based workshop, Prevention

\section{Introduction}

Diabetes mellitus is a chronic metabolic disorder ${ }^{[1]}$ with an estimated worldwide prevalence of $2.8 \%$ (171 million) in 2000 , predicted to increase to $4.4 \%$ (366 million) by $2030 .^{[2]}$ One complication associated with poor metabolic control is diabetic foot. Adequate metabolic control as well as preventive measures are necessary to avoid or delay this complication.

The American Diabetes Association and the International Consensus on Diabetic Foot have defined diabetic patients at risk of foot ulcers as those who show any of the following characteristics: a history of foot ulcer or amputation, long term diabetes ( $>10$ years), loss of visual acuity, neuropathy or vasculopathy, orthopedic foot disorders (biomechanics), prominent hyperkeratosis on plantar pressure areas, severe ungueal pathology, decreased flexion of the vertebral column, renal insufficiency and personal and social factors (such as advanced age, social isolation and economic problems). ${ }^{[3]}$

In a study conducted in the United States Health Care system, the incidence of foot ulcers in diabetic patients was $6 \%$, and $0.5 \%$ for cases of lower limb amputation. Furthermore, among patients with amputations, the reported prevalence of vascular complications ranges between $46 \%$ and $65 \%$. Finally, the death rate in patients with diabetic foot is $11 \%$,

\footnotetext{
*Correspondence: Gladys Pérez-Borges; Email: ajimenezsosa@gmail.com; Address: Department of Clinical Nutrition and Endocrinology, Hospital Universitario de Canarias, Ofra s/n. La Cuesta, La Laguna 38320, Tenerife, Spain.
} 
and $22 \%$ for patients with a history of lower limb amputation. ${ }^{[4]}$ The prevalence of Type 2 diabetes in the Canary Islands (Spain) has been reported to be $12 \% .{ }^{[5]}$ The records of our hospital, which is the reference centre for a population of approximately 1,050, 000 inhabitants, show that between 2007 and 2008, 176 patients suffered non-traumatic lower-limb amputation, of whom 119 (67.6\%) were diabetic patients. ${ }^{[6]}$

Amputations are major physical and psychological problems, which also consume considerable economic resources. ${ }^{[7]}$ Most amputations can be avoided by adopting adequate educational strategies. In fact, a high percentage of non-traumatic amputations derive from negligent attitudes, inadequate preventive care and even from misconceptions by patients. ${ }^{[8]}$

Educational interventions are effective for reducing and preventing diabetes complications including coma (70\%-80\%), amputations $(50 \%-70 \%)$ and hospitalization rate. ${ }^{[9]}$ Short text messages sent to patients' mobile phones can positively influence control of glycated hemoglobin (HbA1c) levels. ${ }^{[10]}$ In addition, face-to-face education is a very effective procedure for the transmission of knowledge on methods to prevent diabetic foot complications. ${ }^{[11]}$ However, individualized face-to-face education requires certain resources which are not available in every health care system.

Dorresteijn et al. (2014) ${ }^{[12]}$ reviewed the evidence regarding the effects of patient education on the prevention of foot ulcers in patients with diabetes mellitus. They included prospective randomised controlled trials that evaluated educational programmes for preventing foot ulcers in people with diabetes mellitus.

Of the 12 RCTs included, the effect of patient education on primary end points was reported in only five. Pooling of outcome data was precluded by marked, mainly clinical, heterogeneity. Three studies did not demonstrate any effect of education on the primary end points, but were most likely underpowered. Patient foot care knowledge was improved in the short term in five of eight RCTs in which this outcome was assessed, as was patients' self-reported self-care behaviour in the short term in seven of nine RCTs. Callus, nail problems and fungal infections improved in only one of five RCTs. Only one of the included RCTs was at low risk of bias. Dorresteijn conclude that there is insufficient evidence that limited patient education alone is effective in achieving clinically relevant reductions in the incidence of foot ulcers and lower-limb amputations.

We have observed at our Endocrinology Department that some patients who received basic group or individual education did not carry out proper care measures required for the prevention of foot lesions. Therefore, we created a nurseled educational intervention using group-based workshops, in order to intensify education as a key element to avoid lesions or relapses that can lead to lower limb amputation. By means of practical examples and group training, our aim was to improve foot care skills of the patients and their families. Our framework can be resumed stating that primary prevention must be the main objective in nurse educational practice to prevent diabetic foot, and the impact of educational programs should combine long-term evaluation and physical exploration.

The aim of this study was to evaluate the effect of a nurseled educational intervention using group-based workshops in terms of changes in diabetic patient knowledge and skills to prevent foot lesions.

\section{Methods}

The study was performed according to the principles of the Declaration of Helsinsky. All patients gave informed consent and the study was approved by the Clinical Research Ethics Committee of the Hospital Universitario de Canarias.

\subsection{Patients and study design}

This was a prospective before and after study with educational intervention. It was carried out between November 2007 and April 2013. In the Endocrinology Department of the Hospital Universitario de Canarias, all diabetic patients are frequently evaluated for foot lesions. Those who showed any risk factors for diabetic foot as defined by the American Diabetes Association (2005) were selected for inclusion in the present study.

The study was designed to evaluate the long-term effect of the intervention on the prevention of diabetes-related foot lesions. Thus, we planned a follow-up of 60 months with a minimum period of 12 months after intervention. We include a flowchart of the study with more detailed information (see Figure 1).

The initial assessment was made based on clinical interview and physical examination in order to identify patients with possible risk of foot lesions and to select subjects for the group-based workshop. Patient knowledge and skills on foot care were evaluated using a department-elaborated questionnaire (baseline score, maximum 50). The questionnaire was developed in the Endocrinology Department of our Hospital and validated by an expert panel of the Hospital. The patients selected attended two group sessions of two hours each, during two consecutive days. The groups comprised 6-8 patients who could each be accompanied by one relative. The first session consisted of 30 minutes of theoretical content (concepts of health and foot risk, skin health and care, foot inspection and patient's reaction to injuries) and 85 minutes of practical exercises (demonstration and selection of hygiene instruments; cleaning practice, drying, hydration and nail cutting; preparation of proper condi- 
tions for inspection; simulation of caring for a specific lesion). The second session had the same time duration and included both theoretical and practical content. The theoretical content included: information on socks, stockings and footwear, as well as general and specific exercises for the prevention of foot complications. The practical content included: evaluation and selection of clothing and footwear, self-drawn outline of their own foot for use in shoe purchase (given their reduced neuropathic sensitivity), specific practical exercises, a clinical case of risk factors, simulation of sensory reduction and a demonstration of how to detect sensory loss.

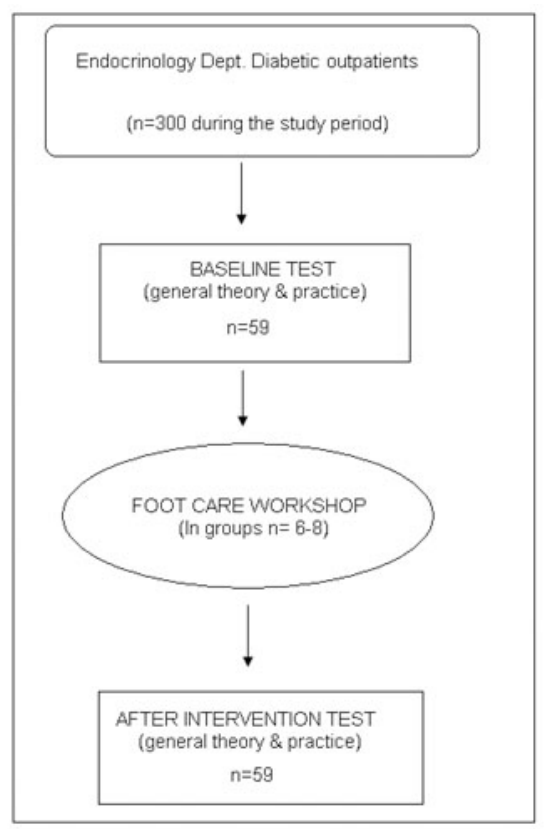

Figure 1: Flowchart of the study

For the theoretical content, a lecture and an interactive method were used when explaining the slides that included this content. The practical topics were presented with exercises which were carried out by the participants. When the sessions ended, all the participants received informative material and a summary of the contents.

Patient knowledge and skills were evaluated using a 5-item care scale, each scored from 0 to 10 points. The five modifiable variables of preventive care (maximum score 10 points each) were: inspection, socks and footwear, nail cutting, hygiene, footcare habits and foot lesion care. The study also recorded values for the following aspects: anthropometric measures, laboratory data, evidence of neuropathic and vascular symptoms, foot skin morphological alterations and cardiovascular risk factors. All patients were informed about the assessment which would serve to detect risk factors for diabetic foot and that the results would be used to monitor and study these factors.

\subsection{Statistical analysis}

The results involving quantitative variables are expressed as means and standard deviations; qualitative variables are expressed as frequencies and percentages. Normality assumption was tested with Kolmogorov-Smirnov-test.

The before-and-after comparisons of both the quantitative and qualitative variables were performed using Student's $t$ test for repeated measures, Wilcoxon or McNemar tests, as appropriate. Values of $P<.05$ were considered as significant. We used a one-sided $p$ value to compare foot lesions before and after the interventions. Statistical analysis was performed using SPSS v.17.0 (Chicago, IL, USA) and StatXact 5.0.3 (Cytel Co., MA, USA).

\section{Results}

Fifty nine consecutive patients aged $60 \pm 10$ years were included in the study; $32(54.2 \%)$ men and $27(45.8 \%)$ women; 11 (18.6\%) with diabetes type I and $48(81.4 \%)$ with diabetes type II). All showed at least one risk factor for diabetic foot. At baseline, average disease duration was $17 \pm 10$ years. Twenty six $(45.6 \%)$ showed arterial hypertension, dyslipidemia and overweight. Thirty six $(61 \%)$ patients had paresthesia and $28(68.3 \%)$ had sensory loss in at least one lower limb. Mean follow-up time after the intervention was $41.1 \pm 10$ months.

With regard to vascular signs and symptoms, more than $33 \%$ of the subjects showed decreased temperature of the lower limbs and dry skin or claudication. With respect to diabetic foot characteristics, nearly $58 \%$ of the subjects showed thickened nails, orthopedic alterations, foot deformation and areas of hyperkeratosis or calluses.

Table 1 shows clinical and biochemical data of the study patients before and after the educational intervention; no significant differences were observed in smoking status, alcohol, glycosylated $\mathrm{Hb}$, total or HDL cholesterol, triglycerides or BMI.

Table 2 shows the mean scores for knowledge and skill of the 5 items evaluated, before and after the educational intervention. Significant changes were found in all the variables studied: inspection, footwear, hygiene and nail cutting, healthy habits and lesion care. Mean total score improved from $25 \pm 11.0$ at baseline to $40 \pm 7.0(P<.001)$ after the educational program. With regard to the general exercises (any kind of exercise, 3 or 4 days per week), no change was observed after the program [26 of $40(62 \%)$ versus 25 of $40(63.3 \%) ; P=.76)]$, but a dramatic increase in specific foot exercises was noted [2 of $40(5 \%)$ versus 22 of $40(55.1 \%) ; P<.001)]$. 
Table 1: Biochemical characteristics and modifiable risk factors

\begin{tabular}{llll}
\hline & Pre-workshop $(\mathbf{n}=\mathbf{5 9})$ & Post-workshop $(\mathbf{n}=\mathbf{5 9})$ & P value \\
\hline Alcohol consumption - no (\%) & $13(22)$ & $9(18.4)$ & .55 \\
Smoking status_-no (\%) & $6(10.3)$ & $6(12.2)$ & .99 \\
HBa1C* (\%) & $8.4 \pm 1.85$ & $8.2 \pm 1.43$ & .56 \\
Total cholesterol (mg/dl) & $172 \pm 31$ & $168 \pm 41$ & .56 \\
HDL-cholesterol (mg/dl) & $50 \pm 20$ & $50 \pm 17$ & .65 \\
Triglycerides (mg/dl) & $154 \pm 68$ & $143 \pm 55$ & .67 \\
Body Mass Index & $3 \pm 5.8$ & $32 \pm 5.2$ & .20 \\
\hline
\end{tabular}

*Glycosylated hemoglobin

Table 2: Preventive care evaluation scores before and after the group-based workshop intervention

\begin{tabular}{llll}
\hline & Pre-workshop (baseline) $(\mathbf{n}=\mathbf{5 9})$ & Post-workshop $(\mathbf{n}=\mathbf{5 9})$ & P value \\
\hline Inspection & $5 \pm 4.5$ & $8.3 \pm 3.3$ & $<.001$ \\
Socks and footwear & $5 \pm 3.1$ & $8.7 \pm 1.6$ & $<.001$ \\
Nail-cutting & $5 \pm 1.8$ & $8 \pm 1.6$ & $<.001$ \\
General habits & $5 \pm 2.5$ & $8 \pm 1.8$ & $<.001$ \\
Lesion care & $5 \pm 4.1$ & $8 \pm 3.4$ & .001 \\
Total score & $\mathbf{2 5} \pm \mathbf{1 1}$ & $\mathbf{4 0} \pm .7$ & $<.001$ \\
\hline
\end{tabular}

During follow-up, 11 (18.6\%) of the patients suffered a foot lesion, more specifically on the instep. After the intervention, the incidence of foot lesions declined with respect to baseline [20/59 (33.9\%) vs. 11/59 (18.6\%); $P=.03]$.

\section{Discussion}

In this study we found that group-based workshops improved knowledge of modifiable factors for the prevention of diabetic foot: inspection, footwear, nail-cutting and hygiene, and, more importantly, the intervention resulted in decreased incidence of foot ulcers.

Diabetic foot is a serious and severe complication of diabetes. Its treatment and prevention require collaboration between a multidisciplinary group of professionals and the patient. Some discrepancy exist regarding the exercises to be recommended to patients. According to McGill (2005), ${ }^{[13]}$ exercises that involve bearing weight, including the patients' own bodyweight, should not be recommended. Instead, exercises such as cycling and swimming are advised in order to make exercising easier and to protect the foot from pressure.

One out of four patients in the study reported receiving some information on foot care previously, but it was only after attending this educational program that a significant improvement in preventive foot care was observed. The scores obtained for the factors studied were higher after the educational program, indicating a positive effect on preventive care and modifiable risk factors of diabetic foot. This indicates the utility of workshops such as that implemented in our institution.

Published by Sciedu Press
Many risk factors have been related with diabetic foot such us: peripheral neuropathy, micro-angiopathy, smoking, and cardiovascular risk factors. Peripheral neuropathy is a fundamental factor in the physiopathology of diabetic foot. It results in paresthesia, with diminished pain reaction, tactile pressure, thermal and vibration perception, all of which are normally important to avoid foot lesions. In our study, peripheral neuropathy was observed in $85.4 \%$ of our patients. In this regard, Camp-Fauli (2002) ${ }^{[14]}$ observed that neuropathy is the triggering factor in foot ulcers in $85 \%-90 \%$ of cases. Macro and micro-angiopathy produce claudication and sensitivity disorders in diabetic patients. These signs and symptoms were observed in our group of patients, but no traumatic lesions were detected during follow up. From this it is inferred that the group-workshop exerted an influence in some way to avoid traumatic lesions associated with macro and micro-angiopathy.

Dyslipidemia was observed in more than half of the patients studied, which coincides with a previous study where other authors found a relationship between lipid parameters and peripheral arterial disease. ${ }^{[15]}$

Despite the impact of educational programs on improving quality of life and reducing social costs, podiatrist cover in Spain's Public Health Care system is not included. These professionals are an important part of the team, as well as nurses specialized in diabetes education. Doubts about the role of education in preventing chronic diabetes complications may still exist. However, $85 \%$ of foot-related complications can be prevented with proper education and adequate podiatrist care. ${ }^{[16]}$ 
All diabetic subjects should be periodically evaluated to identify high risk situations and be able to guide them by monitoring and studying modifiable risk factors. When the program ended, it was found that the group-based workshops improved patient awareness and skills in preventive care. For this reason, we propose permanent application of this educational program to all patients at risk of diabetic foot attended at our Endocrinology Department.

\section{Conclusions}

Patients at risk attending a diabetic foot group-based workshop retain the knowledge, show positive behaviour and a lower incidence of vascular complications 1 to 5 years af- ter the educational intervention. The intervention resulted in improved long-term care adherence in diabetic patients at risk of foot ulcers and reduced the incidence of foot lesions.

\section{Acknowledgements}

We thank Lourdes Rodríguez-Hernández, Esteban PorriniBalzaretti, Michael Lee McLean, Alfonso J. López Alba and Alejandro Jiménez-Sosa for their collaboration in this research.

\section{Conflicts of Interest Disclosure}

The authors declare that there is no conflict of interest statement.

\section{References}

[1] Danaei G, Finucane MM, Lu Y, et al. Global Burden of Metabolic Risk Factors of Chronic Diseases Collaborating Group (Blood Glucose. National, regional, and global trends in fasting plasma glucose and diabetes prevalence since 1980: systematic analysis of health examination surveys and epidemiological studies with 370 countryyears and 2.7 million participants. Lancet. 2011; 378(9785): 31-40. http://dx.doi.org/10.1016/S0140-6736(11)60679-X

[2] Wild S, Roglic G, Green A, et al. Global Prevalence of Diabetes Estimates for the year 2000 and projections for 2030. Diabetes Care. 2004; 27(5): 1047-1053. http://dx.doi.org/10.2337/diaca re.27.5.1047

[3] American Diabetes Association. Standards of Medical Care in Diabetes. Diabetes Care. 2005; 28(1): S4-S36. PMid:15618112

[4] Margolis DJ, Malay DS, Hoffstad OJ, et al. Incidence of Diabetic Foot Ulcer and Lower Extremity Amputation Among Medicare Beneficiaries, 2006 to 2008: Data Points \#2. Data Points Publication Series. Rockville (MD): Agency for Healthcare Research and Quality (US).

[5] Cabrera-de-León A, Rodríguez-Pérez M del C, Almeida-González D, et al. Presentación de la cohorte "CDC de Canarias": objetivos, diseño y resultados preliminares. Rev. Esp. Salud Publica. 2008; 82(5): 519-534. PMid:19039505 http://dx.doi.org/10.1590 /S1135-57272008000500007

[6] Registro del Hospital Universitario de Canarias. Conjunto mínimo de base de datos del HUC (CMBD) del 2007-2008. Procedimiento 84.1X (amputación no traumática) con diagnóstico de diabetes. Ed. Hospital Universitario de Canarias. 2009.
[7] The DCCT Research Group. The effect intensive of treatment of diabetes on the development and progresión of long-term complications in IDDM. N Engl J med. 1993; 329(14): 977-986. PMid:8366922 http://dx.doi.org/10.1056/NEJM199309303291401

[8] Suárez-Pérez R, García-Glez R, Álvarez R, et al. Conocimientos, destrezas y conductas ante el cuidado de los pies en un grupo de amputados diabéticos. Rev Cubana Endocrinol. 2001; (2): 93-104.

[9] Viadé-Juliá J, Anglada-Barceló J, Asunción-Márquez J, et al. Pié diabético. Guía práctica para la prevención, evaluación y tratamiento. Ed. Médica Panamericana, S. A. Madrid, España. 2006.

[10] Hee-Sung K. Impact of Web-based nurse's education on glycosylated haemoglobin in type 2 diabetic patients. J Clin Nurs. 2007; 16(7): 1361-1366. PMid:17584355 http://dx.doi.org/10.11 $11 / j \cdot 1365-2702.2007 .01506 . x$

[11] Ko IS, Lee TH, Kim GS, et al. Effects of visiting nurses'individually tailored education for low-income adult diabetic patients in Korea. Public Health Nurs. 2011; 28(5): 429-437. PMid:22092426

[12] Dorresteijn JA1, Kriegsman DM, Assendelft WJ, et al. Patient education for preventing diabetic foot ulceration. Cochrane Database Syst Rev. 2014; 12: CD001488. PMid:25514250

[13] McGill M. Foot-care education for people with diabetes: a major challenge. Diabetes. Voice. 2005; (50): 36-39.

[14] Camp-Fauli A. Cuidados en el pie diabético. Ed. Smith and Nephew, S.A. Valencia; España. 2002.

[15] Vigna GB, Fellin R. Dyslipidemia in peripheral vascular disease. Curr Opin Lipidol. 1996; 7(4): 254-259. PMid:8883501 http: //dx.doi.org/10.1097/00041433-199608000-00012

[16] Van Acker K, Foster A. Achieving excellence in diabetic foot care, one step at a time. Diabetes Voice. 2005; (50): 17-19. 